\title{
Adverbials with Floating and Fixed Semantic Scope
}

\author{
Marina V. Filipenko \\ VINITI (Moscow), Russian Academy of Science \\ tertitsk@tertitski.pvt.msu.su
}

\begin{abstract}
The present study offers the analysis of the role of adverbials in the semantic structure of a sentence. To clarify this role new notions "Adverbials with floating and fixed semantic scope" are proposed. This classification also can clarify the role of adverbials from the point of view of the division into arguments vs. adjuncts.
\end{abstract}

1. Two independent foundations are mixed in the definition of adverbials: on the one hand, adverbials are a class of words, they are a lexical class; on the other hand, adverbials are modifiers. A modifier is a characteristic of a word when it is used in a sentence, it's a functional or semantic category, but not a lexical one (cf. Ramat \& Ricca 1998).

2. The characteristic which an adverbial gives to a situation can be an inner one and an "outer" one. If an adverbial describes a characteristic of the situation as such, we call such adverbial a verb-adverbial or a predicate modifier (Thomason \& Stalnaker 1973, Bartsch 1976), cf.

(1) He answered wisely (carelessly, strangely)

(2) He refused loudly.

And if an adverbial gives to a situation an "outer" characteristic - in this case the adverbial is a sentence-modifier, or a sentence-adverbial, for example:

(3) He wisely (carelessly, strangely) kept silent.

(4) He carelessly rang at apartment 5 < and not apartment $6>$.

There is also the third main class of adverbials - so called grading adverbials (cf., for instance, Bartsch 1976), cf. the example of adverbials in a grading construction:

\section{He left the room carelessly (strangely, wisely) early.}

But the division of adverbials into verb- and sentence-modifiers has weak points. The first problem is (and many authors note it, cf., for instance, Dik 1972) that, in fact, most of adverbial words function as sentence-adverbials and as verb-adverbials as well, cf. wisely in (3) and (1). It means that the division of adverbials into verb- and sentence-adverbials is not the division of words but the division of types of the usages of the adverbial in a sentence.

At the same time, many adverbials considered as manner adverbials (or as verbmodifiers) can not be used as sentence-modifiers (or as grading adverbials), cf. loudly, low, 
drowsily, etc.: in sentence (2) the adverbial loudly has only manner-interpretation ("He refused in a loud voice", "The way he refused was loud"), and can not be interpreted as a sentence adverbial (*It was loud that he refused, *The event "he refused" was loud); cf. also implausible expressions *loudly early, *drowsily good. So, there is a difference between wisely in the (1) and loudly in the (2) though both of them are verb-modifiers, and the notion "verb-modifier" doesn't make this difference clear.

The second problem connected with the division of adverbials into verb- and sentencemodifiers is the occurrence of adverbials as arguments of a verb, like in the sentence (Bach 1980):

The first peace accord lasted for five vears.

The adverbial expression for five years here is an argument of a verb 'last'. But usually we don't consider arguments to be modifiers.

3. The difference of adverbials in (1), (3) and (5) can be explained by two ways:

- as the difference of lexical meanings of adverbials,

- as the difference of adverbial scope.

If we accept the first explanation, we must treat the adverbials in the sentences (1), (3) and (5) as different lexemes. And this is the most popular decision. So, the sentence-adverbials in the sentence (3) get one meaning, and the adverbials in the sentence (1) get another meaning (they are manner adverbials here). According to this decision, the volume of adverbial scope is fixed in the meaning of the adverbial and we need to divide a particular adverbial word into as many lexemes as many volumes of the scope it has.

But I think that this decision can not satisfy us completely. First of all, because of the multiplication of adverbial lexemes. Many linguists note as an intuitively doubtless fact that in the sentences like (1), (3) and (5) an adverbial has only one, but not three meanings. Besides, it is well known that often the scope of a sentence-adverbial is not a situation as a whole, but only a communicatively important, rhematic fragment of a situation (Lang 1979, Koktova 1986). Let's compare the sentences (7) and (8):

He carelessly promised to arrive $<$ instead of keeping silent $>$.

\section{He carelessly promised to arrive $<$ instead of to phone $>$.}

In both sentences the adverbial carelessly plays the role of a sentence-modifier, so it must be the same lexeme. But in the sentence (7) the characteristic 'carelessly' is predicated to the fact of the promise; and in the sentence (8) carelessly characterises the choice of the content of the promise. So, the volumes of the adverbial scope in these sentences are different, and this difference is not explained with the lexical meaning of the sentence adverbial carelessly. Thus, the multiplication of lexical meanings is an instrument which is not good enough for captivating how to find the adverbial scope.

Thus, in classification of adverbials as verb and sentence modifiers the two foundations are mixed: the division of words according to their lexical meanings and the division of words according to the volume of their scope in a sentence. 
4. I think that these two foundations should be treated separately. I propose to treat an adverbial word as a united lexeme, as a word with one meaning. (Indeed, the meaning of an adverbial word can became more concrete, so, it changes in some context types - but not due to changing of adverbial scope.) And as for the rules for finding the adverbial scope in a sentence - they must be investigated and formulated apart, the scope isn't fixed in the meaning of an adverbial. This approach let us to make the semantic links between an adverbial and its scope more clear, in particular, it let us to see that in reality different types of adverbial verbmodifiers modify a verb in different ways.

Adverbial words can be divided according to the rules for finding their semantic scope in a sentence. There are two main classes: adverbials with floating and fixed scope. This classification of adverbials demonstrates that the difference between adverbials like wisely and like loudly (both of them can be used as a traditional "manner" adverbial) is not accidental and has semantic foundation. In all their usages adverbials like wisely play the same role in the semantic structure of a sentence (namely, they have a operator-like nature), and the role of adverbials like loudly is quite different: adverbials like loudly should be considered as, in a sense, (optional) arguments, cf. such classification with about 1100 Russian "manner" adverbials in Filipenko 1994.

5. Adverbial words like carelessly, wisely are adverbials with floating scope because they can characterise semantically different components of the situation described by a sentence. Usually they characterise a communicatively important fragment of the situation or, to speak more precisely: they characterise a choice which is usually made by the controlling subject - the choice between ways of implementation of the situation. For instance, in sentence (8) a communicatively important fragment is "to arrive": the choice of the content of the promise is characterised as 'careless'. As for the sentence

He carelessly promised to arrive at 5 o'clock <instead 6>,

it's the time of an arrival what is the scope of the adverbial carelessly.

Particles like not, even, only, and modal words like of course, naturally, and may be are also adverbials with floating scope. For instance, the particle only can characterise different components of the situation described by a sentence like an adressee:

(10) I showed the letter only to Jim,

or a subject:

Only Peter knew it,

or an object :

(12) I read only newspapers, etc.

The linguistic behaviour of adverbials with floating scope concerns the topic/focus organisation of a sentence: these adverbials can characterise semantically different components of a sentence, and the choice of a relevant component usually depends on communicative organisation of an utterance. These adverbials can co-occur with semantically different verbs; in 
other terms, their co-occurrence is very broad. We can say: he carelessly came in / thought / overslept / counted on and what's not.

We can not specify the grammatical features of components which form the scope ofsuch adverbials because of the diversity of these components.

All these features of adverbials with floating scope are determined by the fact that these adverbials do not denote any "participants" of a situation described by a sentence, they describe an (evaluation) element which is "outside" of this situation, they have an operatorlike nature.

6. The second class of adverbials are adverbials like loudly, adverbials with fixed scope. Adverbials with fixed scope play quite a different role in a sentence, they do not characterise one or another component of a situation (like adverbials with floating scope do). Adverbials like loudly describe such components themselves, they describe a "participant" (often "optional") of a situation described by a sentence, and this "participant" is strictly fixed for a particular adverbial. For instance, for loudly, low it is "the degree of loudness", for drowsily "the state of the subject's consciousness", etc. Information about such a "participant" is a part of the lexical meaning of the adverbial. A certain semantic type of verb has its own set of such "participants", and this set as a whole forms the "manner", the way of realisation of a situation described by a corresponding verb. If the semantic structure of the verb $V$ has not got the corresponding "participant", the verb doesn't co-occur with the adverbial. For instance, we can not say *sleep loudly or *hang loudly, because there is not a parameter " the degree of loudness" in the situations described by the verbs 'sleep' or 'hang'. Thus, the co-occurence of adverbials with fixed scope is not so broad and the information about topic/focus organisation is irrelevant for finding their scope.

Thus, the division "Adverbials with floating vs. fixed scope" is a division of words (and not usages of words in different syntactic constructions). And this division shows itself, for instance, in the character of semantic constraints on the use of the adverbial.

7. Semantic constraints which govern the use of adverbials with fixed scope concern the inner structure of the situation $\mathrm{P}$ as such: for instance, we can say that the movement situations 'run', 'go', 'swim' and so on have the parameter "speed", but the situations 'sleep', 'keep silent' do not have this parameter, this "participant" - and we can say it without paying attention to the context of the concrete implementations of these situations.

On the other hand, the scope of adverbials like only, wisely etc. is not the "parameter" components of the situation $\mathrm{P}$ as such, rather their scope is the particular values of the corresponding parameters. Then, semantic constraints which govern the use of adverbials with floating scope concern first of all not the semantic structure of the situation $\mathrm{P}$ but the context of the implementation of one or another element of the situation described by a sentence.

For instance, the particle only cannot modify all elements of a situation but only an element which is associated with a set of elements and can be opposed to them by a certain feature. For example, in the sentence

\section{Among the pupils only Peter had heard about Wittgenstein}

we can use only, because this particle modifies the element ('Peter') which is associated with a set of elements ('the pupils') and opposed to them by the feature 'to have heard about 
Wittgenstein'. If the context does not satisfy the conditions above, the use of only is impossible. So, we can not say

(14) There were an ink-pot, a blotter and sheets of letterhead paper on the table.?? Only the sheets were put in a pile.

The use of only is impossible in this context, because it's not clear to which elements the modified element 'the sheets' is opposed by the feature 'to be put in a pile'.

The independence of semantic constraints which govern the use of adverbials with floating scope from the semantics of the verb $V$, and their links with the "outside" context of the utterance are the most evident when the scope of such adverbials is constituted by antonymic elements. Thus, the sentences (15) and (16) are plausible to the same extent:

(15) Jane was in a carelessly shot / long dress,

(16) John carelessly keep silent / carelessly interfered with the conversation.

So, the semantic constraints which govern the use of adverbials with floating scope do not concern the situation $P$ as such, but the "outside" context of the utterance.

The difference between the traditional and proposed classifications of adverbials is illustrated with the table.

\begin{tabular}{|c|c|c|c|}
\hline $\begin{array}{l}\text { Number of the } \\
\text { exemple }\end{array}$ & $\begin{array}{l}\text { adverbial/to which class } \\
\text { the adverbial belongs }\end{array}$ & $\begin{array}{l}\text { in the traditional } \\
\text { classification }\end{array}$ & $\begin{array}{l}\text { in the proposed } \\
\text { classification }\end{array}$ \\
\hline 6 & for (five years) & & \multirow{8}{*}{$\begin{array}{l}\text { adverbial with fixed } \\
\text { scope }\end{array}$} \\
\hline 17 & at (five) & $?(=$ argument, not & \\
\hline 17 & about (midday) & modifier of a verb) & \\
\hline 20 & over (the bridge) & & \\
\hline$\overline{18 a}$ & \multirow{7}{*}{$\begin{array}{l}\text { at (night) } \\
\text { about (midday) } \\
\text { for (five years) } \\
\text { loudly } \\
\text { wisely } \\
\text { carelessly } \\
\text { strangely }\end{array}$} & \multirow{7}{*}{ verb-modifier } & \\
\hline $18 \mathrm{~b}$ & & & \\
\hline 19 & & & \\
\hline 2 & & & \\
\hline 1 & & & \multirow{9}{*}{$\begin{array}{l}\text { adverbial with } \\
\text { floating scope }\end{array}$} \\
\hline 1 & & & \\
\hline 1 & & & \\
\hline 3 & wisely & & \\
\hline $3,4,7$ & & & \\
\hline $8,9,16$ & carelessly & sentence-modifier & \\
\hline 3 & strangely & & \\
\hline $10,11,12$ & only & & \\
\hline $\begin{array}{l}15,5 \\
5\end{array}$ & $\begin{array}{l}\text { carelessly } \\
\text { wisley, strangely }\end{array}$ & grading adverbial & \\
\hline
\end{tabular}

8. Let's see now, what the role of adverbials with floating and fixed scope is in a sentence from the point of view of the division into arguments vs. adjuncts?

The term "adjunct" and its equivalents in French and Russian linguistics are different in some way. In the Russian tradition we don't speak about "adjuncts", but about "circumstances", in 
the French tradition it's "sirconstants". The English term "adjunct" stresses the syntactic role of the word: an adjunct - it's something adjunctive - adjunctive to a process, to an event, etc. And Russian and French terms have a semantic nature: "circumstances"/ "circonstants" are predicated to a situation described in a sentence. In fact, the Russian notion "circumstances" are not so broad as the English term "adjuncts". "Circumstances" are adverbial modifiers of time, of place, of manner, of instrument. So, first of all by "adjuncts of a situation", "circumstances" I mean a situation described by a verb. These adjuncts are close to arguments, so they are the most important among the adjuncts when we speak about the division into arguments vs. adjuncts. Now, let's see what is the role of adverbials with floating and fixed scope in a sentence from the point of view of the division into arguments vs. adjuncts.

8.1 As for adverbials with fixed scope, they may be arguments or adjuncts, and in both cases they play a similar role.

Adverbials with fixed scope may have either the status of an argument of the verb, as in (17), or the status of an adjunct, as in (18).

\section{The crisis began at night / about midday,}

\section{a. It rains at night / about midday, \\ b. We packed our luggage at night / about midday,}

In both cases the scope of adverbials is the corresponding "parameter" component, or "thematic role", of the situation-type denoted by a verb. For (17), and (18) it is the component 'time of the situation'. The status of this component in the semantic structure of a particular verb depends on the verb. For example, the time-parameter has the status of an "argument" with the verb 'begin' and the status of "adjunct" with the verbs 'rain' and 'pack'. But in either case, the adverbial with fixed scope describes a particular value of that parameter.

So, then a verb is combined with an adverbial with fixed scope, no matter whether the adverbial plays the role of the argument of the verb or of an adjunct, the semantic interpretation of the resulting combination is very similar in both cases. This similarity of the semantics of the combination is caused by the fact that adverbials with fixed scope, like typical arguments, are strictly connected with a specific component, or thematic role, in the semantic structure of the verb.

But in the usual treatment of adverbials, this resemblance is not taken into consideration. In the semantic representation of an utterance, an adverbial with fixed scope is normally treated either as subordinated to the verb or as subordinating the verb, depending on the particular verb. That is, an adverbial is treated sometimes as an adjunct which subordinates a certain semantic component of the verb, and sometimes as an argument, an expression filling in a certain semantic parameter, a variable of the verb. As for the notion "adjunct", usually it does not presuppose the idea of an inherent link of the adjunct with the semantics of the verb. This is absolutely correct for adverbials with floating scope but not so evident in a case of adverbials with fixed scope.

Adverbial with fixed scope in any of its uses can be treated as describing a semantic "participant" of the situation-type corresponding to the verb. If this "participant" is more important, more salient ("obligatory") in the situation-type V, the adverbial is treated as "an argument" of the verb; and if this "participant" is not so important ("optional") in the situation-type V (= if it has a low communicative "weight" in the semantic structure of the verb), the adverbial is treated as "an adjunct" of the verb. 
Cf. McConnell-Ginet 1982 where adverbs are treated like variable-binding operators which introduce the "variable" which they "bind", an adverb gives to a verb a corresponding argument place. I think that it's relevant only for adverbs with fixed scope.

8.2 As for adverbials with floating scope, they don't describe any particular "participant", any parameter of the situation described in a sentence. They are an "outside" element in the relation of the situation $\mathrm{P}$ described in a sentence. Thus, the adverbials with floating scope particles, adverbs like wisely, strangely - must not be treated, from a semantic point of view, as arguments or as adjuncts (= this is as expressions describing "participants" of the situation P). They have an operator-like nature. I note that such treatment of adverbials with floating scope continues Tesnière's tradition, $\mathrm{cf}$. his analysis of French words like ne ... pas 'not': these words are not treated as "adjuncts", as "sirconstants" - in his analysis particles means something else, not "circumstances" (Tesnière 1959).

9. Finally, I should point out a very important aspect of the problem.. Above I proposed to treat adverbials with fixed scope (following McConnell-Ginet 1982) as describing a semantic "participant" of a situation described by a verb, when a verb has a special argument place for an adverbial. I have to say that in fact the picture is more complicated.

In a general case, the verb denotes a situation-type $\mathrm{V}$, the adverbial describes a "participant" of a situation-type P, and often V and P are identical (cf. (2), (6), (17)-(19)). But in some sentences an adverbial describes a participant of another situation, not of the situation described by a verb ( $=$ the adverbial (expression) with fixed scope supposes the situation-type $\mathrm{P})$. Then $\mathrm{P}$ and $\mathrm{V}$ are different situations.

For instance, which situation is modified by the adverbial expression over the bridge in $(20) ?$

(20) Sam lives (V) over the bridge $(\mathrm{P})$.

Over always supposes a type of movement with an initial and final positions. But the verb live doesn't mean a movement. 'Live' is a static situation. So, the adverbial expression over the bridge doesn't mean a participant of a situation described by a verb, it means a participant of another situation, a situation of movement which must be explicitly presented in the semantic representation of the sentence. This problem is discussed in detail in Filipenko 1997, Dölling 1999.

\section{References}

Bach, E. (1980): In defence of passive. In: Linguistics and Philosophy 3, 297-341.

Bartsch, Renate (1976): The grammar of adverbials. A study in the semantics and syntax of adverbial constructions. Amsterdam.

Dik, S.C. (1972): The semantic Representation of Manner Adverbials. In: Kraak A. (ed.) Linguistics in the Netherlands 1972-1973, 1, 96-121. Amsterdam.

Dölling, Johannes (1999): Flexibility in Adverbial Modification: A General Approach. In: Extended Conference Abstracts: "Approaching the Grammar of Adjuncts". Sept. 22-25, 1999. University of Oslo.

Filipenko, Marina V. (1994): Logical-semantic Representation of Manner Adverbials. Ph.D. thesis. Moscow, Institute of linguistics (Russian Academy of Science). (in Russian)

- (1997): About hierarchy of aspectual characteristics in a clause. In: Voprosy jazykoznanija, 5, 121-134. (in Russian)

Koktova, E. (1986): Sentence adverbials in a functional description. - Pragmatics \& Beyond VII:2, Amsterdam. 
Lang, Ewald ( 1979): Zum Status der Satzadverbiale. In: Slovo a slovesnost, 40/3, 200-213.

McConnell-Ginet, S. (1982): Adverbs and logical form, Language 58, 144-184.

Ramat, P. \& Ricca, D. (1998): Sentence adverbs in the languages of Europe. In: Johan van der Auwera with Dónall P.Ó Baoill (eds.). Adverbial Constructions in the Languages of Europe. Berlin; New York: Mouton de Gruyter, 187-275.

Tesnière, Lucien (1959): Eléments de syntaxe structurale. Paris: Klincksieck.

Thomason, R. \& Stalnaker, R. (1973): A semantic theory of adverbs. In: Linguistic Inquiry. Cambridge (Mass.), $4 / 2,195-220$. 